all the essential knowledge and up-to-date information lucidly written with ample reference to methods of tracing of contacts, public health problems and the control of tuberculosis as a national and world-wide problem.

One of the most attractive aspects of the book is the recognition paid in almost every chapter to the history of medicine. Each subject is introduced with a brief account of the development of our knowledge from early times up to the present day, an approach which, cumulatively, gives the student a wide insight into disease processes and their treatment. There is a small and up-to-date bibliography at the end of each chapter for those who are interested in reading for themselves the original works which have resulted in the sum total of our medical knowledge.

The paper and binding are best described as handsome. The printing and arrangement are quite irreproachable and the illustrations, diagrams and reproduced $X$-rays and photographs are almost always clear and usually add to the understanding of the text. Though this is a valuable book on a consultant's desk it is perhaps the best single volume textbook that exists for the practitioner. Its one real drawback is its price.

\section{A SHORT TEXTBOOK OF RADIOTHERAPY FOR TECHNICIANS AND STUDENTS}

By J. WALTER, M.A., B.M., M.R.C.P., D.M.R.E., and H. Miller, M.A., Ph.D., F.Inst.P. Pp. xii +444 , with 199 illustrations. London : J. \& A. Churchill. I950. 28s.

This book fulfils a definite need and deserves to be widely used. It is well produced and has a large number of good illustrations. Written primarily for radiographers whose needs are constantly kept in mind, it should also find a wider circle of readers. House surgeons to radiotherapeutic departments, surgeons and physicians who are interested in radiotherapy will find much helpful information. The authors have taken great trouble in explaining the meaning of terms they use and even give the derivation of medical words. It does, however, contain rather too much for the student radiographer to digest without help, and in order to understand the intricacies of radiation therapy fully it should be supplemented by lectures of the right type.

The structure of matter and the physical properties of $X$-rays and radioactive materials are dealt with in the first part of the book as well as the biological effects of radiation. Two chapters are devoted to the methods of applying $\mathrm{X}$-rays and radium, followed by an excellent chapter on dosage and the principles of treatment. A few of the important malignant and non-malignant lesions are discussed and the various techniques used in their treatment by radiation are described and well illustrated. As it states in a very disarming preface, the wide difference in modern techniques and also in the education and training of radiographers makes it impossible to please all. However, the methods described in this book are up to date and are those used in many of the best centres.

The modern clinician who wishes to read a short textbook on this subject could not do better than get this book.

E.L.G.H.

\section{SCHISTOSOMIASIS IN SOUTH CENTRAL AFRICA}

By Michael Gelfand, M.D., M.R.C.P. Pp. 239. London : H. K. Lewis. Cape Town : The Post-Graduate Press by Juta \& Co. Ltd. 1950. 25s.

This is a valuable monograph for all those working on schistosomiasis by the author of that interesting book 'The Sick African.' Like most monographs the inevitable repetition does not lead to easy reading, but the author has summarized his conclusions at the end of each chapter adequately and well.

Dr. Gelfand's findings differ from those of previous workers in Egypt. $\mathrm{He}$ is in the fortunate position of having ready access to all the pathological material submitted to the Salisbury laboratory, and being able to compare the findings in Europeans and Africans.

He employed the digestion technique in 4 per cent., caustic potash for rectal and vesical biopsy snippings and extended it to all post-mortem material. He shows that multilobar cirrhosis of the liver is no commoner in endemic than in non endemic areas where the same dietary deficiencies operate, and he is sceptical about the role bilharziasis plays in the aetiology of cancer of the bladder and rectum, basing his conclusions on the fact that in Salisbury, Rhodesia, the incidence of bladder cancer is higher in Europeans than Africans, whilst the bilharzial incidence is as 1 to $4 \cdot 3$.

Dr. Gelfand calls his monograph a clinicopathological study, but surely in as extensive a monograph as this the question of treatment should be included. There are one or two curious omissions, no word is mentioned of the value of prostatic massage prior to the passage of urine to increase the chances of finding schistosome eggs, a method most pathologists have found of help in European cases where the infection is light, and no mention is made of the value of the complement fixation test in diagnosis. These deficiencies should be remedied in the next edition and an index should be added to the bibliography to enhance the value of this useful monograph.

T.C.M.

\section{REGIONAL ILEITIS}

By Burrill B. Crohn, M.D. Pp. viii +229 , with 74 illustrations. London: Staples Press Ltd. I 950. 3os.

In 1932 Crohn and his collaborators first described regional ileitis as an entity. Since then he has continued to study the disease in all its clinical 